\title{
Pathogenicity and Pyrenocine Production of Curvularia inaequalis Isolated from Zoysia Grass
}

\author{
Jin-Cheol Kim, Gyung Ja Choi, and Heung Tae Kim, Senior Scientists, Hyun-Ju Kim, Research Associate, and \\ Kwang Yun Cho, Director, Agrochemicals Screening Division, Screening and Toxicology Center, Korea Research \\ Institute of Chemical Technology, Yusong, P.O. Box 107, Taejon 305-606, Korea
}

\begin{abstract}
Kim, J.-C., Choi, G. J., Kim, H. T., Kim, H.-J., and Cho, K. Y. 2000. Pathogenicity and pyrenocine production of Curvularia inaequalis isolated from zoysia grass. Plant Dis. 84:684-688.

Five isolates of Curvularia inaequalis were obtained from blighted leaves of zoysia grass. The optimal growth temperature of the pathogen was $30^{\circ} \mathrm{C}$ and all isolates caused foliar blighting symptoms on zoysia grass, bent grass, and bermuda grass. Phytotoxic substances were associated with pathogenicity. Two phytotoxins were isolated from liquid cultures of $C$. inaequalis by ethyl acetate extraction and repeated silica gel column chromatography. On the basis of mass and nuclear magnetic resonance spectral analyses, the compounds were identified as pyrenocines A and B, phytotoxins produced by Pyrenochaeta terrestris. Pyrenocine A caused leaf necrosis in a leaf-wounding bioassay and inhibited growth of all plants tested in a whole plant test. Large crab grass and fall panicum were most susceptible to pyrenocine A. Pyrenocines A and B also caused significant electrolyte leakage from leaf tissues of bermuda grass. Pyrenocine B exhibited much weaker phytotoxic activity than pyrenocine A in all bioassays performed. Both compounds caused leaf tip dieback symptoms in turf grass plants similar to symptoms observed in the field. Thus, pyrenocines A and B are thought to be involved in the development of Curvularia blight disease of turfgrasses caused by $C$. inaequalis.
\end{abstract}

Additional keywords: Curvularia blight, patch disease

Zoysia grass (Zoysia japonica Steud.) is a warm-season turf grass. It is predominantly used in home lawns, grounds, and golf course fairways in Korea. Although it is subject to disease injury by various plant pathogens, fewer diseases have been reported on zoysia grass than on other turf grasses (1). A severe large patch-type disease showing blighting symptoms was observed in numerous lawn grounds and golf courses composed of zoysia grass in the early summer of 1998 in Korea during unusually hot weather. Irregularly shaped patches ranging from $30 \mathrm{~cm}$ to nearly $1 \mathrm{~m}$ in diameter began to occur in late May and disease increased gradually as daily maximum temperatures rose from 25 to $35^{\circ} \mathrm{C}$. Foliar symptoms of chlorosis, leaf tip dieback, blight, and reddish-brown margins separating healthy from diseased tissues were observed on diseased plants. The etiology of this disease in zoysia grass has not been well defined; therefore, we investigated the etiology of the disease and de-

Corresponding author: J.-C. Kim

E-mail: kjinc@pado.krict.re.kr

J.-C. Kim and G. J. Choi contributed equally to the paper.

Accepted for publication 6 March 2000.

Publication no. D-2000-0406-02R

(c) 2000 The American Phytopathological Society termined that Curvularia inaequalis (Shear) Boedijn could cause the blighting symptoms observed on zoysia grass.

Although eight Curvularia spp., including $C$. trifolii, $C$. protuberata, C. eragrostidis, $C$. intermedia, $C$. penniseti, $C$. lunata, $C$. senegalense, and $C$. geniculata, have been reported as the cause of blight of turf grasses (14), there has been considerable debate on the potential of Curvularia spp. to incite disease on turf grasses $(2,4,6,9,11)$. For example, Brown et al. (2) reported that $C$. protuberata, $C$. intermedia, C. lunata, and C. geniculata caused leaf tip dieback, leaf spot lesions, and crown and leaf blighting on cultivars of Poa pratensis, Festuca rubra, and Agrostis palustris, particularly at high temperatures (24 to $33^{\circ} \mathrm{C}$ ). Falloon (4) also demonstrated that $C$. trifolii could cause severe disease of turf grasses at temperatures between 25 and $35^{\circ} \mathrm{C}$. Mower (9) and Hodges (6), however, failed to show pathogenicity of $C$. lunata and $C$. geniculata, and Muchovej and Couch (11) showed that $C$. lunata could colonize heatstressed or old clipped leaves, but not juvenile or mature leaves.

On the other hand, many toxins produced by plant pathogens are involved in disease development. An example is pyrenocine phytotoxins that are produced by Pyrenochaeta terrestris, the causal agent of pink root disease of onion (12,13,15-17). Pyrenocines $\mathrm{A}, \mathrm{B}$, and $\mathrm{C}$ show varying degrees of phytotoxicity and are thought to be associated with the development of onion pink root disease (17).

The purpose of this study was to (i) isolate and identify isolates of Curvularia spp. from diseased zoysia grass tissues, (ii) determine the pathogenicity of the isolates on three turf grasses, (iii) isolate and identify phytotoxic substances produced by the isolates, and (iv) examine the phytotoxicity of the compounds to various plants, including turf grasses.

\section{MATERIALS AND METHODS}

Fungal isolation and identification. Isolation of Curvularia spp. was attempted from leaves of diseased zoysia grass collected from golf course fairways and lawn grounds in Taejon, Korea in late May 1998. Turf samples were washed in sterile distilled water to remove soil and then 1to 2-cm sections of leaves, showing incipient to moderately advanced lesions, were removed with a sterile scalpel. The pieces were disinfested in $0.5 \% \mathrm{NaOCl}$ for $1 \mathrm{~min}$, rinsed in sterile water, and placed on onefourth strength potato-dextrose agar (PDA) amended with streptomycin ( $200 \mathrm{mg} / \mathrm{liter})$. Five isolates of Curvularia spp. were obtained from the diseased tissues collected from a golf course fairway (isolate YS) and four lawn grounds (isolates KR-1, 2, 3, and 4) and transferred to PDA slant tubes and distilled water tubes, which were stored at $4^{\circ} \mathrm{C}$

The isolates were incubated on PDA plates at $28^{\circ} \mathrm{C}$ for 15 days with lighting for $12 \mathrm{~h}$ daily. Mycelial fragments and conidia were collected, placed in lactophenol on a glass slide, and used for taxonomic identification of each isolate. Five isolates were identified to species level based on the criteria described by Ellis (3), such as presence or absence of a protuberant hilum on conidia, shape and size of conidia, and number of conidial septa.

Temperature effects on radial growth rate in culture were determined for all five isolates. Mycelial agar discs, $6 \mathrm{~mm}$ in diameter, were cut from vegetative areas of 5-day-old PDA cultures grown at $28^{\circ} \mathrm{C}$. Single discs were placed onto PDA plates and four plates of each isolate were incubated at each of eight temperatures between 15 and $36^{\circ} \mathrm{C}$ for 7 days. Colony diameters were then measured. The experiment was repeated once. 
Pathogenicity of $C$. inaequalis. Pathogenicity experiments were conducted using zoysia grass, bent grass, and bermuda grass. Healthy stolons of zoysia grass were collected from field plots at a lawn ground. Stolon sections containing 10 shoots were transferred to plastic pots $(4.8 \mathrm{~cm}$ in diameter by $5 \mathrm{~cm}$ deep) containing a steamed clay loam soil:peat:perlite mixture $(2: 2: 1)$ at $25 \pm 5^{\circ} \mathrm{C}$ in a greenhouse. The zoysia grass plants were allowed to grow for 2 weeks before inoculation. Bent grass and bermuda grass seeds were sown in plastic pots $(4.8 \mathrm{~cm}$ in diameter by $5 \mathrm{~cm}$ deep) containing the $2: 2: 1$ soil mixture. The pots were incubated for 3 weeks in the greenhouse prior to inoculation.

Each fungal isolate was grown on PDA for 14 days in the dark. Conidia were removed from the surface of fungal colonies with distilled water and the spore suspensions were adjusted to contain $5 \times 10^{5}$ conidia/ml. The potted turf grass plants were inoculated by spraying a spore suspension of each $C$. inaequalis isolate on the foliage and crowns and the pots were incubated in a moist chamber at $30^{\circ} \mathrm{C}$ for 2 days. Control pots were sprayed with distilled water alone. The pots were then transferred to the greenhouse and incubated for 10 days.

Disease severity was rated on a 0 -to- 5 scale using a slight modification of a previously published method (4), where $0=$ no symptoms, $1=$ leaf tip dieback of 0 to 5 $\mathrm{mm}, 2=$ leaf tip dieback $>5 \mathrm{~mm}, 3=$ chlorotic leaf lesions plus leaf tip dieback, $4=>50 \%$ tillers with leaf sheath lesions, and $5=>50 \%$ tillers with dead leaves. Pots were arranged as a randomized complete block with five replications per treatment. The experiment was repeated once and results shown are the averages of two runs with five replicates each.

Isolation of pyrenocines $\mathrm{A}$ and $\mathrm{B}$. Erlenmeyer flasks $(250 \mathrm{ml})$, each containing $100 \mathrm{ml}$ of potato-dextrose broth (PDB) medium, were inoculated with mycelial agar discs from 5-day-old PDA plates of $C$. inaequalis YS. The flasks were incubated for 10 days at $25^{\circ} \mathrm{C}$ with an agitation of $150 \mathrm{rpm}$, then 10 liters of PDB culture was centrifuged at $5,000 \mathrm{rpm}$ for $15 \mathrm{~min}$. The supernatant was extracted three times with an equal volume of ethyl acetate and then concentrated to dryness.

The ethyl acetate extract ( $1.8 \mathrm{~g}$ ) was dissolved in chloroform-methanol (98:2, $\mathrm{vol} / \mathrm{vol})$ and loaded onto a silica gel column $(3.6 \mathrm{~cm}$ i.d. by $60 \mathrm{~cm})$ containing 160 $\mathrm{g}$ of silica gel (Kiesel gel 60, 70/230 mesh; E. Merck, Darmstadt, Germany). The column was eluted with chloroform-methanol (98:2, vol/vol) and collected in 15-ml fractions with a fraction collector. The fractions were monitored by thin-layer chromatography and reduced to four fractions called F1, F2, F3, and F4, which were bioassayed in the leaf-wounding test. Both F2 and F4 caused necrotic brown lesions, and each of these two fractions was purified further. The phytotoxic F2 fraction (276.3 mg) was suspended in chloroformmethanol $(98: 2, \mathrm{vol} / \mathrm{vol})$ and loaded onto a silica gel column $(3.2 \mathrm{~cm}$ i.d. by $45 \mathrm{~cm}$; Kiesel gel 60, 230/400 mesh, 100 g; E. Merck), which was eluted with the chloroform-methanol solvent. The column chromatography yielded $185 \mathrm{mg}$ of pyrenocine $\mathrm{A}$ as a colorless solid. F4 fraction (147.2 mg) was dissolved in chloroformmethanol (95:5, vol/vol) and also applied onto a silica gel column $(2.8 \mathrm{~cm}$ i.d. by 45 $\mathrm{cm}$ ) containing $60 \mathrm{~g}$ of silica gel (Kiesel gel 60, 230/400 mesh; E. Merck). The column was eluted with chloroformmethanol (95:5, vol/vol) and $86 \mathrm{mg}$ of pure pyrenocine $\mathrm{B}$ was isolated.

Spectral measurements. UV spectroscopy was recorded in a methanol solution on a Shimadzu UV-2401PC spectrophotometer (Shimadzu Co., Tokyo, Japan). Low-resolution (LR) mass spectra were recorded on a double-focusing high-resolution (HR) mass spectrometer (JEOL JMSDX303; JEOL Ltd., Tokyo, Japan) at an accelerating voltage of $10 \mathrm{kV}$. The sample was introduced via a direct-insertion probe. The LR electron impact (EI) mass spectrum was recorded at $70 \mathrm{eV}$ and a source temperature of $200{ }^{\circ} \mathrm{C}$. ${ }^{1} \mathrm{H}$ - and ${ }^{13} \mathrm{C}-\mathrm{NMR}$ spectra were recorded in $\mathrm{CDCl}_{3}$ on a Bruker AMX-500 (500 MHz) NMR spectrometer (Bruker Analytische Messtechnik $\mathrm{GmbH}$, Rheinstetten, Germany). Spectra were referenced to tetramethylsilane (TMS) $\left({ }^{1} \mathrm{H}\right)$ or to solvent signals $\left({ }^{13} \mathrm{C}\right)$.

Phytotoxicity tests of pyrenocines A and $\mathbf{B}$. The phytotoxic activities of pyrenocines to various plants were tested by using a leaf-wounding assay, a whole plant assay, and a cellular electrolyte leakage test. Zoysia grass, rice (Oryza sativa), barley (Hordem sativum), corn (Zea mays), soybean (Glycine max), shattercane (Sorghum bicolar), goose grass (Eleusine indica), cocklebur (Xanthium strumarium), and velvet-leaf (Abutilon theophrasti) were used for the leaf-wounding assay. The plants ( 2 weeks old) were grown in a greenhouse and centers of detached plant leaves (5-cm sections) were wounded with a pin. The damaged leaf surfaces immediately were covered with $5 \mu \mathrm{l}$ of each toxin solution per pin hole. Pyrenocines A and B were separately dissolved in methanol and diluted with distilled water to give a final toxin concentration of $1 \mathrm{mM}$. The control was $2 \%$ methanol in distilled water. The treated leaf blades were subsequently incubated in a sealed petri dish containing moistened filter paper and, after $72 \mathrm{~h}$ at $24^{\circ} \mathrm{C}$, phytotoxicity was assessed. Phytotoxicity of pyrenocines $\mathrm{A}$ and $\mathrm{B}$ was assessed based on size of lesion formed around each pin hole. The experimental design was a completely randomized block with three replications and the experiment was conducted twice. Values are the averages of two runs with three replicates each.
Fractions obtained from each separation step during isolation of pyrenocines $\mathrm{A}$ and $\mathrm{B}$ were dissolved in $2 \%$ methanol in distilled water at a concentration of 1,000 $\mu \mathrm{g} / \mathrm{ml}$ and $5-\mu \mathrm{l}$ aliquots was applied to a pin hole of a zoysia grass leaf.

Whole plant tests were done on shattercane, large crab grass (Digitaria sanguinalis), fall panicum (Panicum dichotomiflorum), barnyard grass (Echinochloa crus-galli), quack grass (Agropyron repens), Indian joint-vetch (Aeschynomene indica), velvet-leaf, cocklebur, and bindweed (Calystegia japonica). The nine plant species, consisting of 5 to 10 plants per species, were grown in pots (15.6 by 21 $\mathrm{cm}, 4 \mathrm{~cm}$ deep) containing sandy loam soil for 2 weeks in a greenhouse. Plants were treated by spraying plants in each pot with $14 \mathrm{ml}$ of each toxin solution at a concentration of $500 \mu \mathrm{g} / \mathrm{ml}$. The toxin solution was dissolved in $60 \%$ acetone containing $0.1 \%$ Tween 20 and the control plants were treated with $60 \%$ acetone containing $0.1 \%$ Tween 20. After treatment, the plants were placed in a ventilated hood overnight to dry the solvent and then transferred to a greenhouse. Phytotoxicity was assessed 4 days after the treatment based on visual observations of symptoms using a 0 -to-100 rating system (5). In this study, pots were arranged as a randomized complete block with three replications per treatment. The entire experiment was repeated and values are the averages of two runs with three replicates each.

For the electrolyte leakage test, 5-mm leaf sections were cut with a razor from bermuda grass plants grown for 1 month in a greenhouse. Leaf sections were washed in $5 \mathrm{ml}$ of $1 \%$ sucrose and $10 \mathrm{mM} 2-(N-$ morpholino)ethanesulfonic acid ( $\mathrm{pH}$ 6.5). The washed sections were then placed in 6cm-diameter petri dishes (approximately $0.15 \mathrm{~g}$ fresh weight of leaf pieces per dish) with $7 \mathrm{ml}$ of medium with pyrenocine $\mathrm{A}$ or $\mathrm{B}$ at concentrations of $0.1 \mathrm{mM}$ or $1 \mathrm{mM}$. Pyrenocines A and B were dissolved in acetone. The control contained the same amount of the solvent without pyrenocine compounds and the final concentration of the solvent in the dishes was $1 \%$ ( $\mathrm{vol} / \mathrm{vol})$. The petri dishes were incubated at $25^{\circ} \mathrm{C}$ in the dark in a growth chamber. The conductivity of each bathing medium was measured periodically using a conductivity meter (Denki Kagaku Keiki Co., Ltd., Tokyo, Japan). Because of differences in background conductivity of different treatment solutions, results were expressed as changes in conductivity from the initial measurement. The experimental design was a completely randomized block with three replications per treatment. The experiment was repeated once and results shown are the averages of two runs with three replicates each.

Production of pyrenocines $A$ and $B$ by five isolates of $\boldsymbol{C}$. inaequalis. Each isolate 
was grown in $100 \mathrm{ml}$ of PDB medium in a 250-ml flask shaken at $150 \mathrm{rpm}$ for 10 days at $25^{\circ} \mathrm{C}$. After incubation, each culture was centrifuged at 5,000 rpm for $15 \mathrm{~min}$ and then $50 \mathrm{ml}$ of the supernatant was removed and extracted two times with an equal volume of ethyl acetate. The extracts were pooled and dried under reduced pressure $(70 \mathrm{~cm} \mathrm{Hg}$ ). The residue was redissolved in $2 \mathrm{ml}$ of methanol and analyzed by highperformance liquid chromatography (HPLC). For the HPLC analysis, the following equipment and conditions were used: instrument, Waters HPLC (Millipore Co., Milliford, MA); $\mu$ Bondapak $\mathrm{C}_{18}$ column (3.9 mm i.d. by $300 \mathrm{~mm}$; particle size, 10 $\mu \mathrm{m}$; Millipore Co.); mobile phase, a lineargradient solvent system of methanol-10 $\mathrm{mM} \mathrm{H}_{3} \mathrm{PO}_{4}(20: 80$, vol/vol) to neat methanol; flow rate, $1 \mathrm{ml} / \mathrm{min}$; UV detector, 273 $\mathrm{nm}$. The retention times of pyrenocines A and $\mathrm{B}$ were 17.8 and $14.6 \mathrm{~min}$, respectively. The experiment was conducted twice with two replications per isolate and values shown are the averages of two runs with two replicates each.

Statistical analysis. Analysis of variance was performed on the data with the PROC GLM procedure (SAS Institute, Cary, NC). If $P>F$ was less than 0.01 , means were separated with the least significant difference (LSD) test at the $P=0.05$ level.
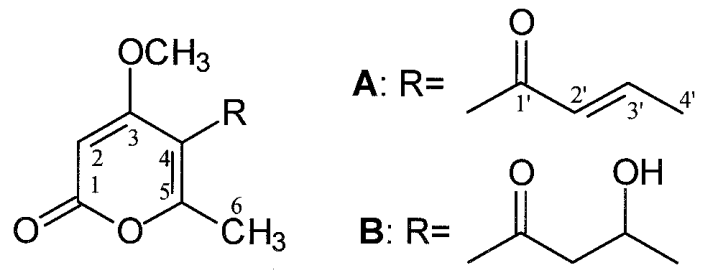

Fig. 1. Chemical structures of pyrenocines A and B produced by Curvularia inaequalis.

Table 1. Effect of Curvularia inaequalis isolates from zoysia grass in Korea on Curvularia blight disease severity of zoysia grass, bent grass, and bermuda grass ${ }^{\mathrm{x}}$

\begin{tabular}{lccc}
\hline & \multicolumn{3}{c}{ Disease severity $^{\mathbf{y}}$} \\
\cline { 2 - 4 } Isolate & Zoysia grass & Bent grass & Bermuda grass \\
\hline YS & 3.8 & 4.9 & 3.7 \\
KR-1 & 3.7 & 4.5 & 4.3 \\
KR-2 & 4.0 & 4.5 & 4.2 \\
KR-3 & 3.8 & 4.2 & 3.7 \\
KR-4 & 3.9 & 4.9 & 4.3 \\
Mean $^{\mathrm{z}}$ & $3.8 \mathrm{~b}$ & $4.6 \mathrm{a}$ & $4.0 \mathrm{~b}$ \\
\hline
\end{tabular}

${ }^{x}$ Pots of grass were inoculated with a conidial suspension $\left(5 \times 10^{5}\right.$ conidia/ml), incubated for $48 \mathrm{~h}$ in a humidity chamber, then maintained in a greenhouse throughout the test.

${ }^{\mathrm{y}}$ Disease severity was rated 10 days after inoculation on a 0 -to- 5 scale, where $0=$ no symptoms, $1=$ leaf tip dieback of 0 to $5 \mathrm{~mm}, 2=$ leaf tip dieback $>5 \mathrm{~mm}, 3=$ chlorotic leaf lesions plus leaf tip dieback, $4=>50 \%$ tillers with leaf sheath lesions, and $5=>50 \%$ tillers with dead leaves. Means are the averages of two runs with five replicates each.

${ }^{\mathrm{z}}$ Means followed by the same letter are not significantly different (least significant difference $=0.21$, $P=0.05$ ) according to the least significant difference test.

Table 2. Phytotoxicity of pyrenocines A and B in a leaf-wounding assay ${ }^{\mathrm{w}}$

\begin{tabular}{lccc}
\hline & \multicolumn{2}{c}{ Lesion size (mm) } & \\
\cline { 2 - 3 } Plant & ${\text { Pyrenocine } \mathbf{A}^{\mathbf{x}}}^{\text {Zoysia grass }}$ & Pyrenocine $\mathbf{B}$ & Lesion type $^{\mathbf{y}}$ \\
\hline Rice & 2.1 & 0.7 & $\mathrm{NB}$ \\
Barley & 3.7 & 0.0 & $\mathrm{NB}$ \\
Corn & 4.0 & 1.0 & $\mathrm{SK}$ \\
Soybean & 4.2 & 0.0 & $\mathrm{NB}$ \\
Shattercane & 3.9 & 1.0 & $\mathrm{NB}$ \\
Goose grass & 5.5 & 1.3 & $\mathrm{DN}$ \\
Cocklebur & 4.1 & 1.2 & $\mathrm{DN}$ \\
Velvet-leaf & 5.1 & 0.0 & $\mathrm{NB}$ \\
LSD $(0.05)^{\mathrm{z}}$ & 2.3 & 0.0 & $\mathrm{DN}$ \\
- & 1.0 & 0.3 & $\ldots$ \\
\hline
\end{tabular}

${ }^{w}$ The 5 -cm sections of leaves of each plant ( 2 weeks old) were placed on moistened filter papers in petri dishes and incubated at $24^{\circ} \mathrm{C}$ for $72 \mathrm{~h}$.

${ }^{x}$ Each compound was dissolved in $2 \%$ methanol in distilled water and $5 \mu \mathrm{l}$ of each toxin solution was applied onto each pin hole, which was made by wounding centers of detached leaves with a pin. After incubation for $72 \mathrm{~h}$, lesion sizes formed around pin holes were measured. Means are the averages of two runs with three replicates each.

y $\mathrm{NB}=$ necrotic brown lesion, $\mathrm{SK}=$ sunken lesion, and $\mathrm{DN}=$ dark necrotic lesion.

${ }^{\mathrm{z}} \mathrm{LSD}=$ least significant difference.

\section{RESULTS}

Symptoms. Curvularia blight of zoysia grass usually starts at the end of June or the beginning of July in Korea. However, in 1998, severe symptoms were observed by the end of May due to the presence of high temperature and frequent rainfall. Symptoms began on zoysia grass as chlorosis of the leaf tip that extended down the leaf blade to the collar. Infected leaves turned brown and finally gray. Reddish-brown margins often separated diseased from healthy tissue. Irregularly shaped patches of blighted zoysia grass coalesced to affect large areas during the summer.

Similar Curvularia isolates were consistently obtained from blighted leaves of zoysia grass samples collected from patches. Five Curvularia isolates were selected for further study.

Identification of species. All five isolates from zoysia grass were identified as C. inaequalis. Of the five isolates, two have been deposited in the International Mycological Institute (IMI) with the assigned number IMI379919 for isolate YS and IMI379920 for isolate KR-1. The optimum temperature for growth of the five isolates on PDA was $30^{\circ} \mathrm{C}$. No differences in growth rate were observed among the isolates.

Pathogenicity. All isolates caused typical brown to dark brown lesions, extending downward from the leaf tip, on zoysia grass, bent grass, and bermuda grass. After 3 days, tip dieback, chlorosis, and extensive blighting of the entire leaf blades was observed. Bent grass was the most susceptible species to $C$. inaequalis (Table 1 ). Disease severity ranged from 4.2 to 4.9 (mean 4.6) on bent grass, from 3.7 to 4.0 (mean 3.8) on zoysia grass, and from 3.7 to 4.3 (mean 4.0) on bermuda grass. Little difference was detected in aggressiveness among the isolates. The pathogen was reisolated from 90 to $100 \%$ of the diseased leaves sampled from each turf grass species. No symptoms were observed on any uninoculated control plants.

Characterization of the phytotoxins. The UV absorption in methanol took place at wavelengths of $225 \mathrm{~nm}(\varepsilon, 12,200)$ and $273 \mathrm{~nm}(\varepsilon, 6,600)$ for pyrenocine $\mathrm{A}$; and $216 \mathrm{~nm}(\varepsilon, 8,500), 258 \mathrm{~nm}(\varepsilon, 6,400)$, and $282 \mathrm{~nm}(\varepsilon, 4,800)$ for pyrenocine B.

The LR-EI mass spectral (MS) data indicated that pyrenocines $\mathrm{A}$ and $\mathrm{B}$ gave molecular ion peaks $\left(\mathrm{M}^{+}\right)$at $\mathrm{m} / \mathrm{z} 208$ and $\mathrm{m} / \mathrm{z} 226$, respectively. ${ }^{13} \mathrm{C}-\mathrm{NMR}$ spectra showed that the two compounds have 15 carbon signals. ${ }^{1} \mathrm{H}-\mathrm{NMR}$ spectra showed the presence of one secondary and two tertiary methyls in the two compounds. After all of the data were compiled, the active substances were identified as pyrenocines A and B. Both compounds were previously reported as phytotoxins and antibiotics from $P$. terrestris, a fungal pathogen of onion pink root disease (Fig. $1 ; 12,13,15,16)$. 
Phytotoxicities of pyrenocines A and B. In the leaf-wounding assay, pyrenocine A exhibited phytotoxic activities to all of the plants tested (Table 2). It caused necrotic brown lesions, sunken lesions, or dark necrotic lesions. Cocklebur and shattercane were most susceptible to pyrenocine A, while zoysia grass and velvet-leaf were relatively resistant. Compared with pyrenocine A, pyrenocine B showed much weaker phytotoxicity to the plants in the leaf-wounding assay.

Pyrenocines A and B also were tested on whole plants. When treated at a concentration of $500 \mu \mathrm{g} / \mathrm{ml}$, pyrenocine A caused a severe growth reduction $(80 \%)$ of large crab grass and fall panicum (Table 3). Of the plants tested, bermuda grass, shattercane, barnyard grass, Indian joint-vetch, and cocklebur were moderately susceptible to pyrenocine $\mathrm{A}$, with a range in growth reduction of 38 to $57 \%$. Quack grass, bent grass, velvet-leaf, and bindweed were relatively tolerant to the phytotoxin, with a growth reduction less than $22 \%$. The symptoms of pyrenocine $\mathrm{A}$ on all the plants were chlorosis followed by necrosis. Pyrenocine $\mathrm{B}$ did not have any phytotoxic effects on the plants tested except for bermuda grass and bent grass. On these two turf grasses, both phytotoxins caused leaf tip dieback symptoms similar to those caused by the pathogen in nature.

Significant electrolyte leakage did not occur before $20 \mathrm{~h}$ of incubation with any bathing medium treated with either pyrenocine $\mathrm{A}$ or $\mathrm{B}$ at concentrations of 0.1 and $1 \mathrm{mM}$ (Fig. 2). Electrolyte leakage from leaf tissues treated with pyrenocine A began to increase after a 20 -h incubation

Table 3. Growth inhibition of various plants by pyrenocines $\mathrm{A}$ and $\mathrm{B}^{\mathrm{x}}$

\begin{tabular}{lcc}
\hline & \multicolumn{2}{c}{ Growth inhibition $(\boldsymbol{\%})$} \\
\cline { 2 - 3 } Plant & $\mathbf{A}^{\mathbf{y}}$ & $\mathbf{B}$ \\
\hline Bermuda grass & 38 & 10 \\
Bent grass & 22 & 5 \\
Shattercane & 57 & 0 \\
Large crab grass & 80 & 0 \\
Fall panicum & 80 & 0 \\
Barnyard grass & 47 & 0 \\
Quack grass & 17 & 0 \\
Indian joint-vetch & 38 & 0 \\
Velvet-leaf & 20 & 0 \\
Cocklebur & 47 & 0 \\
Bindweed & 22 & 0 \\
LSD $(0.05)^{\mathrm{z}}$ & 4.8 & 0.7 \\
\hline
\end{tabular}

${ }^{x}$ Fourteen-day-old plants were treated by spraying each pot with $14 \mathrm{ml}$ of each toxin solution, which was placed in a ventilated hood overnight to dry the solvent, then maintained for 4 days in a greenhouse. Growth inhibition was assessed based on visual observations of symptoms using the 0-to-100 rating system.

${ }^{\mathrm{y}}$ Pyrenocines A and B were dissolved in 60\% acetone containing $0.1 \%$ Tween 20 and applied to plants at $500 \mu \mathrm{g} / \mathrm{ml}$. Means are the averages of two runs of three replicates each.

${ }^{\mathrm{z}} \mathrm{LSD}=$ least significant difference. and reached $705 \mu \mathrm{mho} / \mathrm{cm}$ for $1 \mathrm{mM}$ and $224 \mu \mathrm{mho} / \mathrm{cm}$ for $0.1 \mathrm{mM}$ after a $68-\mathrm{h}$ incubation. Pyrenocine B also caused cellular electrolyte leakage, but its activity was much weaker than that of pyrenocine A.

Production of pyrenocines $A$ and $B$ by C. inaequalis isolates. All five isolates of C. inaequalis produced both pyrenocine compounds (Table 4). Generally, pyrenocine A was more abundant than pyrenocine $\mathrm{B}$ for all isolates.

\section{DISCUSSION}

C. inaequalis was isolated from the diseased leaves of zoysia grass (3). C. inaequalis has not been recorded previously from any turf grass species, but eight other Curvularia spp. are known to be pathogenic to turf grasses (14). The morphological differences between $C$. inaequalis and some other Curvularia spp. are small. Compared with the conidia of $C$. inaequalis, those of $C$. senegalense are smaller (10 to 14 , mean $11.4 \mu \mathrm{m}$ ) by 19 to 30 , mean $24 \mu \mathrm{m}$ ) and more curved (3). Though the conidial sizes of $C$. geniculata and $C$. inaequalis are similar, the conidial shapes of the species are quite different. The conidia of $C$. inaequalis are straight or slightly curved and taper only a little at each end, while those of $C$. geniculata taper gradually from the central cell towards each end (3).

Curvularia spp. isolated from turf grasses can be saprophytes or pathogens. There has been considerable debate on Curvularia spp. as pathogens of turf grasses $(2,6)$. Several reports revealed that high temperature stress of grass leaves leading to senescence was necessary for infection by $C$. lunata $(2,7,10,14)$. Muchovej and Couch (11) reported that $C$. lunata did not infect juvenile or mature leaves, though it colonized heat-stressed and old clipped leaves. In this study, $C$. inaequalis caused a severe blight of the juvenile leaves of bent grass and bermuda grass without leaf clipping or heat stress. Thus, Korean isolates of $C$. inaequalis are pathogenic on turf grasses and may represent a threat to zoysia grass.

The isolates of $C$. inaequalis obtained from diseased zoysia grass also were pathogenic to bent grass and bermuda grass. No major differences in levels of aggressiveness were detected in the $C$. inaequalis isolates, and host specificity

Table 4. Accumulation of Pyrenocines A and B by five isolates of Curvularia inaequalis obtained from zoysia grass ${ }^{\mathrm{Z}}$

\begin{tabular}{lcc}
\hline & \multicolumn{2}{c}{ Concentration $(\boldsymbol{\mu g} / \mathbf{m l})$} \\
\cline { 2 - 3 } Isolate & $\mathbf{A}$ & $\mathbf{B}$ \\
\hline YS & 43.7 & 38.7 \\
KR-1 & 44.7 & 25.0 \\
KR-2 & 34.3 & 30.1 \\
KR-3 & 32.4 & 21.9 \\
KR-4 & 26.7 & 20.7 \\
\hline
\end{tabular}

${ }^{\mathrm{z}}$ Five isolates of $C$. inaequalis obtained from the diseased tissues from a golf course fairway (YS) and four lawn grounds (KR-1, 2, 3, and 4) were incubated in potato-dextrose broth medium for 10 days. The supernatant obtained through centrifugation of each culture was twice extracted with ethyl acetate and then the organic extracts were concentrated to dryness. The residues redissolved in methanol were analyzed by high-performance liquid chromatography. Means are the averages of two runs with two replicates each.

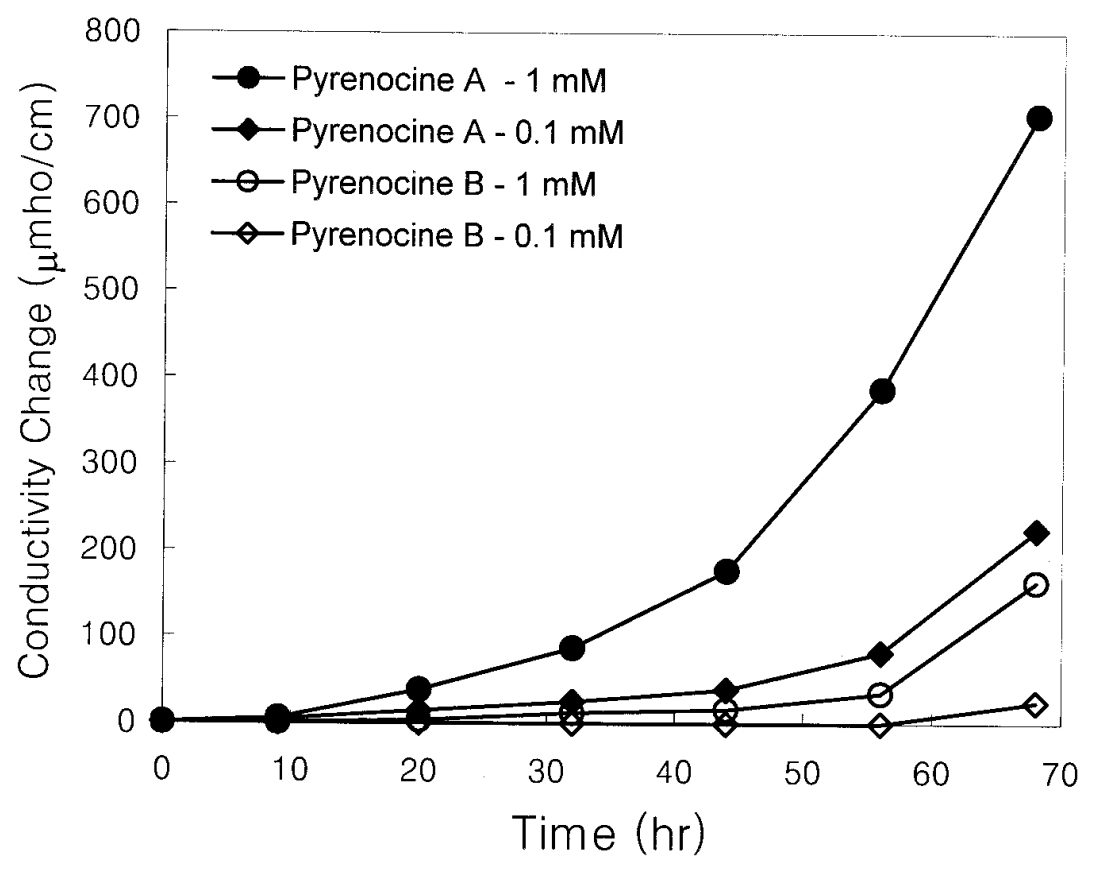

Fig. 2. Effects of pyrenocines A and B on electrolyte leakage from the leaf tissues of bermuda grass. Values are differences between treated and control tissues. 
was not observed. Falloon (4) reported that C. trifolii isolates obtained from various sources differed in virulence on turf grass species and lacked host specificity. Brown et al. (2) also showed that a number of Curvularia isolates collected from various turf grass samples and turf grass seed samples exhibited marked differences in virulence on turf grasses and lack of host specificity. In contrast, Kim et al. (8) reported that $C$. lunata isolates from diseased leaves of bent grass were pathogenic on bent grass but not on zoysia grass.

C. inaequalis isolates produced two pyrones, pyrenocines $\mathrm{A}$ and $\mathrm{B}$. These two toxins exhibited varying degrees of phytotoxicity on turf grasses in a leaf-wounding assay, a whole plant assay, and in a cellular electrolyte leakage test. These toxins were originally reported as phytotoxic metabolites from liquid cultures of $P$. terrestris, the causal agent of pink root of onion $(12,13,15,16)$. On onion, pyrenocine $\mathrm{A}$ is the most toxic form, while pyrenocines B and $\mathrm{C}$ showed little or no phytotoxicity $(12,16,17)$. Pyrenocine A also showed much higher phytotoxicity than pyrenocine $\mathrm{B}$ in the bioassays performed in our study.

In the leaf-wounding assay and the whole plant test, pyrenocine A was phytotoxic to various plants, including turf grasses. This indicates that pyrenocine $\mathrm{A}$ is not a host-specific toxin. Even though the isolates of $C$. inaequalis were pathogenic to turf grasses, they were not the most susceptible plants to the phytotoxins in the bioassays. It is very interesting that pyrenocine $\mathrm{B}$ produced some leaf tip dieback symptoms on bermuda grass and bent grass, but not on other plants in the whole plant test. Our results suggest that both pyrenocine $\mathrm{A}$ and $\mathrm{B}$ may be involved in disease development by $C$. inaequalis in turf grasses.

This is the first report of a causal relationship of $C$. inaequalis with Curvularia blight of zoysia grass, the development of blighting symptoms on juvenile turf grass leaves after inoculation with the fungus, and the production of pyrenocines A and B by the fungus.

\section{ACKNOWLEDGMENTS}

We thank the International Mycological Institute, Surrey, UK, for the identification of Curvularia isolates; J. S. Choi for conducting the whole plant test; and C. S. Lee for advice on the statistical analysis.

\section{LITERATURE CITED}

1. Beard, J. B. ed. 1973. Turfgrass: Science and Culture. Prentice-Hall, Englewood Cliffs, NJ.

2. Brown, G. E., Cole, H., Jr., and Nelson, R. R. 1972. Pathogenicity of Curvularia sp. to turfgrasses. Plant Dis. Rep. 56:59-63.

3. Ellis, M. B. 1971. Dermatiaceous Hypomycetes. Commonwealth Mycological Institute, Surrey, England.

4. Falloon, R. E. 1975. Curvularia trifolii as a high-temperature turfgrass pathogen. N.Z. J. Agric. Res. 19:243-248.

5. Fans, R., Talbert, R., Marx, D., and Crowley, H. 1986. Experimental design and techniques for measuring and analyzing plant responses to weed control practices. Pages 29-46 in: Research Methods in Weed Science. N. D. Camper, ed. The Southern Weed Science Society, Champaign, IL

6. Hodges, C. F. 1972. Interaction of culture age and temperature on germination and growth of Curvularia geniculata and on virulence. Can. J. Bot. 50:2093-2096.

7. Howard, F. L. 1953. Helminthosporium-Curvularia blights of turf and their cure. Golf Course Rep. 21(2):5-9.

8. Kim, H. T., Chung, Y. R., Cho, K. Y., and
Hwang, Y. S. 1992. Identification of Curvularia species isolated from bentgrass (Agrostis palustris) showing leaf blight and environmental factors affecting the disease development. Kor. J. Plant Pathol. 8:75-80.

9. Mower, R. G. 1961. Histological studies of suscept-pathogen relationships of Helminthosporium sativum P.K. and B., Helminthosporium vagans Drech. and Curvularia lunata (Wakk.) Boed. on leaves of Merion and of Common Kentucky bluegrass (Poa pratensis L.). Ph.D. thesis. Cornell University, Ithaca.

10. Muchovej, J. J. 1986. Definition of leaf health in Agrostis palustris at the time of infection and colonization by Curvularia lunata. Ann. Appl. Biol. 109:249-258.

11. Muchovej, J. J., and Couch, H. B. 1987. Colonization of bentgrasss turf by Curvularia lunata after leaf clipping and heat stress. Plant Dis. 71:873-875.

12. Sato, H., Konoma, K., and Sakamura, S. 1979. Phytotoxins produced by onion pink root fungus, Pyrenochaeta terrestris. Agric. Biol. Chem. 43:2409-2411.

13. Sato, H., Konoma, K., Sakamura, S., Furusaki, A., Matsumoto, T., and Matsuzaki, T. 1981. X-ray crystal structure of pyrenocine A, a phytotoxin from Pyrenochaeta terrestris. Agric. Biol. Chem. 45:795-797.

14. Smiley, R. W., Dernoeden, P. H., and Clarke, B. B. 1992. Compendium of turfgrass diseases. American Phytopathological Society, St. Paul, MN.

15. Sparace, S. A., and Mudd, J. B. 1985. The biosynthesis of the pyrenocines in cultures of Pyrenochaeta terrestris. Plant Physiol. 79:308-310.

16. Sparace, S. A., Mudd, J. B., Burke, B. B., and Aasen, A. J. 1984. Pyrenocine C, a phytotoxin-related metabolite produced by the onion pink root pathogen Pyrenochaeta terrestris. Phytochemistry 23:2693-2694.

17. Sparace, S. A., Shahin, E. A., and Mudd, J. B. 1986. Accumulation of pyrenocines in cultures of the onion pink root pathogen Pyrenochaeta terrestris and some observations on their phytotoxicities. Physiol. Mol. Plant Pathol. 28:381-392. 